\title{
Autonomic pain responses during sleep: a study of heart rate variability
}

F. Chouchou ${ }^{1-2 *}$, V. Pichot ${ }^{2}$, C. Perchet 1 , V. Legrain ${ }^{3-4}$, L. Garcia-Larrea ${ }^{1}$, F. Roche ${ }^{2}$, H. Bastuji ${ }^{1}$.

${ }^{1}$ Unité INSERM U879, (Central Integration of Pain), Université Lyon 1, Lyon, France.

${ }^{2}$ Service de Physiologie Clinique, Pole NOL, CHU Nord; Equipe SNA-EPIS, Université Jean Monnet, PRES de Lyon, Saint-Etienne F-42023, France.

3 Department of Experimental-Clinical and Health Psychology, Ghent University, Ghent, Belgium.

${ }^{4}$ Rehabilitation and Physical Medicine Unit, Institue of Neuroscience (INES), Université catholique de Louvain, Louvain-la-Neuve \& Brussels, Belgium.

* Corresponding author: Address : Unité INSERM U879 (Central Integration of Pain), Hôpital neurologique, 59 bd Pinel, Bron F-69677, France, Phone: +33 4723578 28, Fax: +33 472357397.

E-mail: florian.chouchou@etu.univ-lyon1.fr (F. Chouchou).

Original article

Keyword: Pain; Sleep; Heart rate variability; Autonomic nervous system; Wavelet analysis; Laser stimulation 


\begin{abstract}
The autonomic nervous system (ANS) reacts to nociceptive stimulation during sleep, but whether this reaction is contingent to cortical arousal, and whether one of the autonomic arms (sympathetic/parasympathetic) predominates over the other remains unknown. We assessed ANS reactivity to nociceptive stimulation during all sleep stages through heart rate variability, and correlated the results with the presence of cortical arousal measured in concomitant 32channel EEG. Fourteen healthy volunteers underwent whole-night polysomnography during which nociceptive laser stimuli were applied over the hand. RR intervals (RR) and spectral analysis by wavelet transform were performed to assess parasympathetic $\left(\mathrm{HF}^{\mathrm{WV}}\right)$ and sympathetic ( $\mathrm{LF}^{\mathrm{WV}}$ and $\mathrm{LF}^{\mathrm{WV}} / \mathrm{HF}^{\mathrm{WV}}$ ratio) reactivity. During all sleep stages, RR significantly decreased in reaction to nociceptive stimulations, reaching a level similar to that of wakefulness, at the $3^{\text {rd }}$ beat post-stimulus and returning to baseline after 7 beats. This RR decrease was associated with an increase in sympathetic $\mathrm{LF}^{\mathrm{WV}}$ and $\mathrm{LF}^{\mathrm{WV}} / \mathrm{HF}^{\mathrm{WV}}$ ratio without any parasympathetic $\mathrm{HF}^{\mathrm{WV}}$ change. Albeit $\mathrm{RR}$ decrease existed even in the absence of arousals, it was significantly higher when an arousal followed the noxious stimulus. These results suggest that the sympathetic-dependent cardiac activation induced by nociceptive stimuli is modulated by a sleep dependent phenomenon related to cortical activation and not by sleep itself, since it reaches a same intensity whatever the state of vigilance.
\end{abstract}




\section{Introduction}

Pain is known to disrupt sleep in clinical (Moldofsky, 2001; Onen et al. 2005) and experimental conditions (Bastuji et al. 2008; Bentley et al. 2003; Lavigne et al. 2004; Lavigne et al. 2000). In healthy subjects, nociceptive stimuli delivered during sleep have been reported to induce cortical arousals in 27 to $48 \%$ of the cases, according to various factors such as sleep depth and the nature of nociceptive stimuli (Bastuji et al. 2008; Lavigne et al. 2004).

Arousal events are characterized by abrupt changes in central nervous system activity that produce electroencephalographic (EEG) activation and concomitant changes of physiologic parameters under autonomic control, such as RR intervals (RR) (Bonnet and Arand, 1997), blood pressure (BP) (Carrington and Trinder, 2008), ventilation (Trinder et al., 2001b) and systemic vascular resistance (Chaicharn et al., 2008). Previous reports point to a tight relationship between the cortical reaction and the cardiac activation: in cases of spontaneous cortical arousal (Bonnet and Arand, 1997; Gosselin et al., 2002), periodic leg movements (Lavoie et al., 2004; Sforza et al., 2002) or external sensory stimulations (Catcheside et al., 2002; Goff et al., 2008; Morgan et al., 1996), the RR decrease was significantly related to the magnitude of arousal reactions (Sforza et al., 2000; Sforza et al., 2002). Furthermore, it has been suggested that the involvement of the autonomic nervous system (ANS) in cardiac activation could differ with sleep stages, i.e. sympathetic reactivity and parasympathetic withdrawal in sleep stage 2 but sympathetic reactivity only in paradoxical (REM) sleep (Bonnet and Arand 1997).

Changes in RR were also described in response to nociceptive heat thermal stimulations (thermode) applied during nocturnal sleep (Lavigne et al., 2001), suggesting that the ANS remains reactive to painful stimuli during all sleep stages without sizeable difference of reactivity between them. However, whether nociceptive-related cardiac activation is contingent to cortical arousal remains unclear, as well as the exact participation of both sympathetic and parasympathetic systems in this cardiac activation. These issues are of interest when considering possible autonomic dysfunction in patients with chronic pain conditions and sleep disorders.

Accordingly, in the present study we assessed the autonomic reactivity to nociceptive stimuli during all-night sleep and its relationship to both cortical EEG reactivity and sleep stages. We hypothesised that 1) nociceptive stimulation should predominantly induce a sympathetic dependent cardiac reactivity, 2) this cardiac activation should be of higher intensity when stimuli give rise to cortical arousals and 3) should be associated with parasympathetic withdrawal in sleep stage 2 . 
We choose time-frequency analysis of cardiac signals based on wavelet transforms since this method is well adapted to ANS reactivity studies on short periods of data with nonstationary signals (Ducla-Soares et al., 2007; Pichot et al., 1999; Wiklund et al., 1997), and allows to accurately assess the involvement of each autonomic arm (Task Force of the European Society of Cardiology and the North American Society of Pacing and Electrophysiology, 1996; Pagani et al., 1984; Pagani et al., 1992). 


\section{Methods}

\subsection{Participants}

Fourteen healthy volunteers were included in this study (4 women and 10 men; mean age: $32.8 \pm 7.3$ (SD) years). All the subjects were free from any known cardiac abnormalities, neurological or psychiatric disease, insomnia or chronic pain, and none of them was on any psychotropic medication. All subjects scored less than five in each subclass of a general health questionnaire (GHQ-28, (Goldberg and hillier, 1979), French translation: W. Bettschart and M. Bolognini), indicating absence of significant state anxiety or depression. The study was approved by local Ethics Committee (CCPPRB Léon Bérard-Lyon), supported by the French National Agency for Medical Research (INSERM) and performed under informed consent according to the Declaration of Helsinki.

\subsection{Laser stimulation}

Nociceptive radiant heat stimuli were delivered with a Nd:YAP laser (Neodinium: Yttrium Aluminium Perovskite; Stimul 1340 El.En®; wavelength $1.34 \mu \mathrm{m}$; pulse duration $5 \mathrm{~ms}$ ). The laser beam was transmitted from the generator to the stimulating probe via an optical fibre of 10 m length (550 $\mu$ m diameter with SMA-905 connector), which passed through a wall hole from the recording to the sleeping rooms. Stimulus intensity was determined for each participant two days before the sleep experimental session, and controlled before starting the sleep session. Stimuli of graded energy density were delivered, with random 10 to $20 \mathrm{~s}$ interstimulus intervals, on the dorsum of the left or right hands and nociceptive thresholds were obtained using a Likert-type scale, ranging from 0 (no sensation) to 10 (unbearable pain), where level 4 was defined as "pricking, moderately painful". Stimulus energy estimated at or slightly above 4 was used for experimental session and was kept constant during the whole night (see (Bastuji et al., 2008) for more details). Energy densities were set between 50 and 79 $\mathrm{mJ} / \mathrm{mm} 2$. These figures were within the normal values in our laboratory (Perchet et al., 2008), and in accordance with published experimental data using Nd:YAP lasers (Leandri et al., 2006; Truini et al., 2007).

\subsection{Experimental protocol}


The protocol took place in an acoustically and electrically shielded room of the laboratory. To increase sleep pressure, all subjects were deprived to 2-3 hours of sleep the night preceding the experimental session. Estimation of laser stimulus intensity and recording of laser evoked potentials (LEPs) during wakefulness were performed in a quiet room, contiguous to the sleeping area, with the subject seated in an armchair. Then, subjects lay down on a comfortable bed in an isolated laboratory room. A minimum of 20 minutes of sleep was allowed from the first EEG signs of sleep onset to the first laser stimulus. Identification of the different sleep stages (Stage 2 -S2-, Slow Wave Sleep -SWS- and Paradoxical (REM) sleep PS) was done on-line by an expert in sleep studies (HB). This allowed us to stimulate in each sleep stage and to immediately discontinue the sequence if one stimulus awakened the sleeper. A second investigator (VL) entered iteratively the room to deliver laser pulses. Both the sleeping subject and the investigator wore eye protections; the investigator also wore headphones that allowed hearing a sound that announced the laser pulse. If any stimulus awoke the sleeper, the sequence was immediately discontinued. Stimuli were delivered with a mean of $30 \mathrm{~s}$. inter-stimulus intervals during sleep. Subjects were awakened at 7:00 am and a final recording run was done during wakefulness.

\subsection{Electrophysiological recording}

Polygraphic all-night electrophysiological recordings were performed using a Neuroscan ${ }^{\circledR}$ Scan 4.2 (Neuroscan, Charlotte, USA) amplifier and $32 \mathrm{Ag} / \mathrm{AgCl}$ electrodes mounted on an elastic cap (Quickcap®, Neuromedical supplies, Charlotte, USA) designed for the extended International 10-20 System (Nuwer et al., 1998). All EEG electrodes were referred to the nose. In addition to the EEG cap sensors, blinks and saccades were recorded with an electrooculogram (EOG) electrode placed on the supero-lateral right canthus, and the electromyogram (EMG) was recorded using two electrodes over the mentalis muscle in the chin. One further electrode, linked to the common reference, was attached to the skin over the extensor digitorum communis in the left forearm, and was used for limb EMG and electrocardiogram (EKG). The impedance of all electrodes was kept below $5 \mathrm{kOhm}$. The electroencephalographic signal was sampled at $500 \mathrm{~Hz}$, amplified 30,000 times and one-line filtered analogically (pass band (-3dB/oct 0.1-70 Hz)). Simultaneous to each laser pulse, a digital trigger was sent to the EEG recording system and stored along with EEG data, in order to determine off line the exact moment when stimuli took place. Electrophysiological data were recorded continuously between 11:00 pm and 07:00 am and were stored for off-line analysis. 


\subsection{Data analysis}

\subsubsection{Sleep analysis}

Sleep stages were visually scored off-line according to Rechtschaffen and Kales criteria (Rechtschaffen and Kales, 1968) based on 30 s epochs for hypnograms. The occurrence of cortical arousal reactions was checked after each stimulus. Following the ASDA criteria (ASDA, 1992), cortical arousals were defined as bursts of wakefulness cortical activity lasting more than $3 \mathrm{~s}$ and less than $15 \mathrm{~s}$, and were considered as stimulus-related if occurring within $15 \mathrm{~s}$ after stimulus onset. A full awakening was scored when the cortical reaction occurring within the $15 \mathrm{~s}$ after the stimulus lasted more than $15 \mathrm{~s}$. Examples are presented in Figure 1.

\subsubsection{RR intervals evolution analysis}

Peak-to-peak analysis of EKG signal was implemented in order to detect the $\mathrm{R}$ wave of QRS complex in a Matlab® environment (MathWoks, Naticks, MA, USA). A first visual selection was directly performed on EKG data. All undetected QRS, ectopic beats or artefacts were corrected on EKG data or eliminated if correction was not possible; EKG data were ats eliminated from analysis when other laser stimulations, artifacts or ectopic beats occurred in an interval of less than 5 heart beats before and 8 heart beats after the stimulus. Statistic comparisons were performed on the mean of 3 minimal RR between 2 and 7 heart beats poststimulation (mean RR) compared with the mean of the $5 \mathrm{RR}$ pre-stimulation.

\subsubsection{Spectral analysis of RR intervals}

In order to analyse RR both in time and frequency domains, wavelet analysis, applied on RR signal, was performed using the mother function Daubechies 4. The wavelet analysis signal allows following the time evolution of each frequency contained in the signal. Starting from this initial function Daubechies 4, a family of functions was built by dilatation and translocation, which constitute the so-called wavelet frame. A serial list of coefficients called wavelet coefficients was used, which represent the evolution of the correlation between the signal and the chosen wavelet at different levels of analysis (or different ranges of frequencies) all along the signal. The first levels $(2,4,8)$ correspond to a wavelet analysis conducted with a small value of the dilatation factor applied on 2, 4 and 8 RR respectively. Thus these levels represent high-frequency variations in the signal. The last levels $(16,32,64 \ldots)$ correspond to a wavelet analysis conducted with a large value of the dilatation factor applied on 16, 32 and 
64 RR respectively. Consequently these levels represent low-frequency variations in the signal.

According to Task Force of the European Society of Cardiology and the North American Society of Pacing and Electrophysiology (Task Force of the European Society of Cardiology and the North American Society of Pacing and Electrophysiology, 1996), squared wavelet coefficients at levels 2,4 , and 8 (high frequency: $\mathrm{HF}^{\mathrm{WV}}$ ) were used to assess parasympathetic reactivity. Wavelet power coefficient at levels 16 (low frequency: $\mathrm{LF}^{\mathrm{WV}}$ ) was used to assess sympathetic reactivity (see ref (Pichot et al., 1999; Pichot et al., 2001)). In the present study, we kept power coefficient at level 16 only in $\mathrm{LF}^{\mathrm{WV}}$, since inter stimuli intervals were too short to apply the coefficient at level 32. $\mathrm{A} \mathrm{LF}^{\mathrm{WV}} / \mathrm{HF}^{\mathrm{WV}}$ ratio was calculated as the ratio between the wavelet power coefficient at levels 16 on one hand and the sum of the wavelet power coefficients at levels 2,4 , and 8 on the other, to obtain a marker of autonomic nervous system balance. This analysis was performed on $16 \mathrm{RR}$ before and after each stimulus. An example is shown in figure 2.

\subsection{Statistical analysis}

Data were analysed using PASW Statistics 18 (SPSS Inc ${ }^{\circ}$, Chicago, USA) software. Mean $\mathrm{RR}, \mathrm{HF}^{\mathrm{WV}}, \mathrm{LF}^{\mathrm{WV}}$ and $\mathrm{LF} / \mathrm{HF}^{\mathrm{WV}}$ ratio values were submitted to 2 different repeated-measures analyses of variance (ANOVA), each one with 2 within factors and with Greenhouse-Geisser correction of degrees of freedom when appropriate. The first factor was time (pre- vs poststimulation) in both ANOVA while the second factor was: (a) states of vigilance (wakefulness vs S2 vs SWS vs PS) in the first ANOVA and (b) cortical reactivity (arousal vs no reaction) in the second one. Newman-Keuls post-hoc test was performed when appropriate.

The association between cortical arousal duration and each of the three variables (mean $\mathrm{RR}, \mathrm{HF}^{\mathrm{WV}}, \mathrm{LF}^{\mathrm{WV}}$ and $\mathrm{LF} / \mathrm{HF}^{\mathrm{WV}}$ ratio) if significantly modified by the stimulation, were tested by simple regression analyses for continuous variables.

Differences were considered significant when $p<0.05$ and values are expressed as mean \pm SEM. 


\section{Results}

Three out of 14 subjects had to be excluded from analysis: two because they had very few sleep (less than 2.2 hours) and one because his EKG data were missing. Mean sleep duration for the 11 remaining subjects was $397.9 \pm 60.3$ (mean \pm standard deviation $(\mathrm{SD})$ ) minutes (table 1). From a total of 909 laser stimuli delivered, 881 were included in analysis and 28 excluded because of too short inter stimulus intervals for RR analysis or of uncorrected artefacts and ectopic beats. For the whole group, $80.1 \pm 30.6$ stimulations per subject were selected, of which $20.1 \pm 20.2$ were in wakefulness, $29.5 \pm 9.3$ in S2, $21.3 \pm 14.3$ in PS and $9.3 \pm 10.3$ in SWS (table 1). Due to technical problems (see RR intervals evolution analysis in Methods), sleep stages or wakefulness data were missing in some subjects. Then, statistical analysis was performed on 8 subjects for the comparison between states of vigilance and on 11 subjects for the comparison between cortical arousal and absence of cortical arousal.

\subsection{RR intervals and wavelet analysis across states of vigilance}

\subsubsection{RR intervals analysis}

Mean RR varied significantly as a function of time $(F(3,7)=27.78 ; p=0.001)$, whereas there was no significant effect of states of vigilance $(F(3,7)=1.29 p=0.303)$ but an interaction $(F(3,7)=4.62 ; p=0.024)$. RR was significantly decreased after the stimuli as compared to pre-stimuli periods and basal level of RR was lower during wakefulness in comparison with basal level of RR during sleep stages (see figure 3A).

\subsubsection{Wavelet analysis}

$\mathrm{LF}^{\mathrm{WV}}$ was modified significantly as a function of time $(F(3,7)=19.95 ; p=0.003)$ and states of vigilance $(F(3,7)=4.74 ; p=0.033)$ with an interaction between them $(F(3,7)=4.49$; $p=0.040) . \mathrm{LF}^{\mathrm{WV}}$ was significantly increased after the stimuli as compared to pre-stimuli periods. Post-hoc tests showed lower level during wakefulness than those during stage $2(\mathrm{Q}=$ 4.56; $p=0.020)$ and paradoxical sleep $(\mathrm{Q}=4.42 ; p=0.014)$ but not during slow wave sleep $(\mathrm{Q}=1.98 ; p=0.180)$. No difference appeared between sleep stages (stage 2 vs slow wave sleep: $\mathrm{Q}=1.82, \mathrm{p}=0.083$; stage 2 vs paradoxical sleep: $\mathrm{Q}=0.096, \mathrm{p}=0.930$; paradoxical sleep vs slow wave sleep: $\mathrm{Q}=1.73, \mathrm{p}=0.099$ ). These results were illustrated in figures $3 \mathrm{~B}$.

$\mathrm{HF}^{\mathrm{WV}}$ was not significantly modified as a function of states of vigilance $(F(3,7)=2.50 ; p=$ $0.142)$, nor of time $(F(3,7)=0.37 ; p=0.564)$ and there was no interaction $(F(3,7)=1.10 ; p=$ 0.361 ) (see figure $3 \mathrm{C}$ ). 
$\mathrm{LF}^{\mathrm{WV}} / \mathrm{HF}^{\mathrm{WV}}$ ratio was modified significantly as a function of time $(F(3,7)=15.61 ; p=$ $0.006)$ but not states of vigilance $(F(3,7)=2.60 ; p=0.097)$ without interaction between them $(F(3,7)=0.24 ; p=0.782) . \mathrm{LF}^{\mathrm{WV}} / \mathrm{HF}^{\mathrm{WV}}$ was significantly increased after the stimuli as compared to pre-stimuli periods (see figure 3D). These results were illustrated in figures $3 \mathrm{~B}$, $3 C$ and $3 D$.

\subsection{RR intervals and wavelet changes according to cortical arousal}

\subsubsection{RR intervals analysis}

Mean RR was significantly modified as a function of time $(F(1,10)=59.39 ; p<0.001)$ and cortical reactivity $(F(1,10)=30.80 ; p<0.001)$, with an interaction $(F(1,10)=8.20 ; p=0.017)$. RR was significantly decreased after the stimuli as compared to pre-stimuli periods and RR respense in decreased more with cortical arousal in comparison with no cortical reaction (figure $4 \mathrm{~A}$ ).

\subsubsection{Wavelet analysis}

$\mathrm{LF}^{\mathrm{WV}}$ did not vary significantly with cortical reactivity $(F(1,10)=1.26 ; p=0.288)$ whereas there was a significant effect of time $(F(1,10)=8.656 ; p=0.015)$ without an interaction $(F(1,10)=2.44 ; p=0.149) . \mathrm{LF}^{\mathrm{WV}}$ was significantly increased after the stimuli as compared to pre-stimuli periods. These results were illustrated in figures 4B.

$\mathrm{HF}^{\mathrm{WV}}$ was not significantly modified as function of cortical arousal $(F(1,10)=3.58 ; p=$ $0.088)$, of time $(F(1,10)=3.54 ; p=0.089)$ and there was no interaction $(F(1,10)=1.03 ; p=$ 0.334 ) (see figure $4 \mathrm{C}$ ).

$\mathrm{LF}^{\mathrm{WV}} / \mathrm{HF}^{\mathrm{WV}}$ ratio did not vary significantly with cortical reactivity $(F(1,10)=3.38 ; p=$ $0.096)$ whereas there was a significant effect of time $(F(1,10)=16.18 ; p=0.002)$ without an interaction $(F(1,10)=4.53 ; p=0.059)$. These results were illustrated in figures $4 \mathrm{~B}, 4 \mathrm{C}, 4 \mathrm{D}$. $\mathrm{LF}^{\mathrm{WV}} / \mathrm{HF}^{\mathrm{WV}}$ was significantly increased after the stimuli as compared to pre-stimuli periods (see figure 4D).

\subsubsection{Associations between duration of cortical arousal and autonomic indexes}

Simple regression analyses showed no significant association between the duration of cortical arousal, and mean $\mathrm{RR}(\mathrm{t}=0.28, p=0.779$ and $\mathrm{r}<0.01), \mathrm{LF}^{\mathrm{WV}}(\mathrm{t}=-1.07, p=0.28$ and $\mathrm{r}=0.01)$ nor $\mathrm{LF}^{\mathrm{WV}} / \mathrm{HF}^{\mathrm{WV}}$ ratio $(\mathrm{t}=0.54, p=0.593$ and $\mathrm{r}<0.01)$. 


\section{Discussion}

Nociceptive stimulation induced a sympathetic-dependent cardiac activation, which was not modulated by sleep stages, but varied contingently with cortical reactivity. Indeed, cardiac reactivity was found to be higher when nociceptive stimuli produced cortical arousals, even though preserved in absence of subsequent arousals.

\subsection{Cardiac autonomic activation according to the states of vigilance.}

Comparing pre and post stimulus mean heart rate values, Lavigne et al. (2001) have also reported a cardiac activation in reaction to nociceptive stimulations during all sleep stages without any significant difference between them. The present study confirms that autonomic reactivity, well known during wakefulness (Moltner et al., 1990; Paine et al., 2009), is preserved during all sleep stages. Furthermore, the present study was able to characterise the temporal course of pain-related cardiac activation, which begins within the two seconds following the stimulation, reaches its maximum at about five seconds and lasts up to 10 seconds after the stimulation (see figure 3A). Nevertheless, it is interesting to notice that the level reached was indeed the same in sleep and wakefulness since the sleep basal level of cardiac activity is known to be lower than that of wakefulness (Baharav et al., 1995; Bonnet and Arand, 1997; Trinder et al., 2001a; Vanoli et al., 1995; Vaughn et al., 1995; Versace et al., 2003). Thus, this suggests that, whatever the basal state of autonomic system, which depends ef on the states of vigilance, nociceptive stimulations give rise to a the same level of activation whatever the states of vigilance, probably related to the intensity of the stimulation.

This autonomic cardiac reactivity to nociceptive stimuli was mainly due to an increase in sympathetic activation which was the same in all sleep stages. Conversely, in the present study there was no pain-induced modification of parasympathetic activity, as assessed by $\mathrm{HF}^{\mathrm{WV}}$. While sympathetic activation has been documented to a wide variety of sensory stimuli, the participation of parasympathetic system in the response during sleep remains controversial. It was absent in response to pain stimuli in our study (see figure 3C) and to periodic leg movements (Sforza et al., 2005), but present with auditory stimuli (Blasi et al., 2003) or spontaneous arousals in a previous study (Bonnet and Arand, 1997). These discrepancies could be explained by the different kinds of stimulation used, but more probably arise from different methodological approaches. Since parasympathetic activation has slower dynamics than sympathetic arousal, it could have been hidden in our study because of too short inter- 
stimuli intervals precluding its full expression (Sforza et al., 2000). Thus, stimuli of different origins induce a cardiac reflex activation implying essentially sympathetic activity, and with a parasympathetic involvement which seems to be less clear and possibly dependent on stimulus parameters.

\subsection{Sleep autonomic reaction to nociception and the hierarchy of arousal.}

Cardiac ANS reactivity was present even in absence of cortical arousal; but it was significantly greater when the nociceptive stimuli were followed by an arousal (see figure 4). However, as autonomic and cortical responses seem to occur simultaneously, about one second after the stimulus (see figure 4 and (Bastuji et al., 2008)), there is no evidence, in these studies, to suggest that one lead the other.

A recent study in our laboratory has shown that, although nociceptive stimuli were processed by the sleeping cerebral cortex even in absence of arousal (Bastuji et al., 2008), a cognitive component peaking around $500 \mathrm{~ms}$ post-stimulus, was enclosed within the laser evoked potential (LEP) when the stimulations gave rise to subsequent cortical arousals. This result suggests another level of modulation of nociceptive information leading to behavioural reaction and transient interruption of sleep. Thus, the hierarchy in arousal reaction during sleep, previously proposed (Halasz et al., 2004; Sforza et al., 2000), may consist of a first level response with sympathetic dependent cardiac and nociceptive somatosensory cortex activations, and a second one, more sophisticated including a cognitive process of the stimulation, a higher sympathetic activation associated with a cortical arousal.

The mechanisms underlying both autonomic and cortical responses followed by arousals are probably complex and interrelated. First, it has been shown that the autonomic nervous system activity influences the amplitude of LEPs (Edwards et al., 2008). Second, both somatosensory cortical (Bastuji et al., 2008) and cardiac autonomic responses (Bonnet and Arand, 1997; Sforza et al., 1999; Sforza et al., 2000) are known to occur before the "classical" EEG arousal response. Therefore, as nociceptive stimuli are supposed to induce in parallel two cortical activations, one by the nociceptive somatosensory pathway and the other by the vegetative one, we cannot exclude that both activations determined the EEG cortical arousal.

From this point of view, cortical arousal could be considered as the response to a somatosensory-visceral summation when a certain threshold is reached. At that time, when this level is reached, sympathetic cardiac activation seems to have no more influence in the 
intensity of cortical activation, since no association was found between the duration of cortical reactivity and $R R$ intervals decrease in the present study.

However, the question remains why repetitive stimulations of same physical intensity should induce different levels of reactivity during sleep. An extrinsic factor, such as variation in stimulus intensity, cannot be excluded. Although stimulus intensity was supposed to be constant along the experiment, there may have been minor variations of energy received by the hand due to slight position change of the laser pointer or small thermal skin changes during the night. It is also likely that spontaneous changes in the internal system's state during sleep do influence the effect of a same stimulation applied at periods of different reactivity.

Notwithstanding these facts, different levels of reactivity have been reported to happen in reaction to sensory stimuli of constant intensity during a same sleep stage (Bonnet and Moore, 1982), suggesting that these different levels of response could also be related to intrinsic fluctuations of brain activity, actually known to occur during sleep. Paradoxical sleep has phasic and tonic periods, as well as thalamocortical coupling and uncoupling periods (Magnin et al., 2004), while fluctuations in sleep stage 2 and slow wave sleep are related to the occurrence of $\mathrm{K}$ complexes and spindles, cyclic alternative pattern and slow oscillations (Steriade et al., 1993). Furthermore, fluctuations in brain activity are not an exclusive phenomenon of sleep since they were recently shown to modulate somatosensory perception during wakefulness (Boly et al., 2007).

\subsection{Limitations}

Several limitations of this study have to be considered, the first concerning the number of subjects. Although the results were clearly significant, any generalisation is hampered by the limited sample (data obtained from only 11 of 14 subjects). From a technical point of view, our time-frequency spectral analysis of RR intervals was performed without the last power coefficients of $\mathrm{LF}^{\mathrm{WV}}$ band (wavelet coefficient power at level 32) to limit overlap in wavelet power analysis (Pichot et al., 1999). This could have attenuated the $\mathrm{LF}^{\mathrm{WV}}$ increase on statistical grounds. In spite of this, the $\mathrm{LF}^{\mathrm{WV}}$ analysis was highly significant, consistent with the RR changes and with others results obtained from spectral analysis of RR after spontaneous arousals (Bonnet and Arand, 1997), periodic leg movements (Sforza et al., 2005), or auditory stimuli (Blasi et al., 2003).

\subsection{Clinical implications}


In chronic pain condition (Mahowald et al., 1989) when iterative cardiac autonomic response is associated with sleep fragmentation, it may entail a persistent high sympatheticcardiac activity during sleep (Martinez-Lavin et al., 1998) and participate to ANS dysfunction as recently suggested in fibromyalgic patients (Sarzi-Puttini et al., 2006). Wavelet analysis could be applied to chronic pain patients and may bring information on sympathetic-cardiac activity during sleep in several chronic pain syndromes (Thomas et al. 2010). However, an autonomic dysfunction related to sleep fragmentation remains to be demonstrated in chronic pain syndromes with further studies.

In conclusion, the present study suggests that the sympathetically-driven cardiac activation in reaction to somatosensory nociceptive stimulations is preserved during all sleep stages and that a higher cardiac autonomic reactivity is concomitant to cortical arousal. This autonomic reactivity might be considered as the first mechanism that allows potential behavioural response and could take part in occurrence of cortical arousals. Its involvement in persistent autonomic and cardiovascular alterations in chronic pain conditions remains to be ascertained in future investigations.

\section{Acknowledgements}

Florian Chouchou is supported by Novacor company (Rueil Malmaison, France). The work was partly supported by the Fondation pour la Recherche Médicale (FRM) and the Fondation NRJ-Institut de France. 


\section{References}

American Sleep Disorders Association Report. EEG arousals: scoring rules and examples: a preliminary report from the Sleep Disorders Atlas Task Force of the American Sleep Disorders Association. Sleep 1992;15:173-184.

Baharav A, Kotagal S, Gibbons V, Rubin BK, Pratt G, Karin J, Akselrod S. Fluctuations in autonomic nervous activity during sleep displayed by power spectrum analysis of heart rate variability. Neurology 1995;45:1183-1187.

Bastuji H, Perchet C, Legrain V, Montes C, Garcia-Larrea L. Laser evoked responses to painful stimulation persist during sleep and predict subsequent arousals. Pain 2008;137:589-599.

Bentley AJ, Newton S, Zio CD. Sensitivity of sleep stages to painful thermal stimuli. J Sleep Res 2003;12:143-147.

Blasi A, Jo J, Valladares E, Morgan BJ, Skatrud JB, Khoo MC. Cardiovascular variability after arousal from sleep: time-varying spectral analysis. J Appl Physiol 2003;95:13941404.

Boly M, Balteau E, Schnakers C, Degueldre C, Moonen G, Luxen A, Phillips C, Peigneux P, Maquet P, Laureys S. Baseline brain activity fluctuations predict somatosensory perception in humans. Proc Natl Acad Sci U S A 2007;104:12187-12192.

Bonnet $\mathrm{MH}$ and Arand DL. Heart rate variability: sleep stage, time of night, and arousal influences. Electroencephalogr Clin Neurophysiol 1997;102:390-396.

Bonnet MH and Moore SE: The threshold of sleep: perception of sleep as a function of time asleep and auditory threshold. Sleep 1982;5:267-276.

Boscan P, Kasparov S, Paton JF. Somatic nociception activates NK1 receptors in the nucleus tractus solitarii to attenuate the baroreceptor cardiac reflex. Eur J Neurosci 2002;16:907920.

Carrington MJ and Trinder J. Blood pressure and heart rate during continuous experimental sleep fragmentation in healthy adults. Sleep 2008;31:1701-1712.

Catcheside PG, Chiong SC, Mercer J, Saunders NA, McEvoy RD. Noninvasive cardiovascular markers of acoustically induced arousal from non-rapid-eye-movement sleep. Sleep 2002;25:797-804. 
Chaicharn J, Carrington M, Trinder J, Khoo MC. The effects on cardiovascular autonomic control of repetitive arousal from sleep. Sleep 2008;31:93-103.

Ducla-Soares JL, Santos-Bento M, Laranjo S, Andrade A, Ducla-Soares E, Boto JP, SilvaCarvalho L, Rocha I. Wavelet analysis of autonomic outflow of normal subjects on headup tilt, cold pressor test, Valsalva manoeuvre and deep breathing. Exp Physiol 2007;92:677-686.

Edwards L, Inui K, Ring C, Wang X, Kakigi R. Pain-related evoked potentials are modulated across the cardiac cycle. Pain 2008; $137: 488-494$.

Goff EA, O'Driscoll DM, Simonds AK, Trinder J, Morrell MJ. The cardiovascular response to arousal from sleep decreases with age in healthy adults. Sleep 2008;31:1009-1017.

Goldberg DP and Hillier VF. A scaled version of the General Health Questionnaire. Psychol Med 1979;9:139-145.

Gosselin N, Michaud M, Carrier J, Lavigne G, Montplaisir J. Age difference in heart rate changes associated with micro-arousals in humans. Clin Neurophysiol 2002;113:15171521.

Halasz P, Terzano M, Parrino L, Bodizs R. The nature of arousal in sleep. J Sleep Res $2004 ; 13: 1-23$.

Lavigne G, Brousseau M, Kato T, Mayer P, Manzini C, Guitard F, Monplaisir J. Experimental pain perception remains equally active over all sleep stages. Pain 2004;110:646-655.

Lavigne G, Zucconi M, Castronovo C, Manzini C, Marchettini P, Smirne S. Sleep arousal response to experimental thermal stimulation during sleep in human subjects free of pain and sleep problems. Pain 2000;84:283-290.

Lavigne GJ, Zucconi M, Castronovo V, Manzini C, Veglia F, Smirne S, Ferini-Strambi L. Heart rate changes during sleep in response to experimental thermal (nociceptive) stimulations in healthy subjects. Clin Neurophysiol 2001;112:532-535.

Lavoie S, de Bilbao F, Haba-Rubio J, Ibanez V, Sforza E. Influence of sleep stage and wakefulness on spectral EEG activity and heart rate variations around periodic leg movements. Clin Neurophysiol 2004;115:2236-2246.

Leandri M, Saturno M, Spadavecchia L, Iannetti GD, Cruccu G, Truini A. Measurement of skin temperature after infrared laser stimulation. Neurophysiol Clin 2006;36:207-218.

Magnin M, Bastuji H, Garcia-Larrea L, Mauguiere F. Human thalamic medial pulvinar nucleus is not activated during paradoxical sleep. Cereb Cortex 2004;14:858-862. 
Mahowald MW, Mahowald ML, Bundlie SR, Ytterberg SR. Sleep fragmentation in rheumatoid arthritis. Arthritis Rheum 1989;32:974-983.

Martinez-Lavin M, Hermosillo AG, Rosas M, Soto ME. Circadian studies of autonomic nervous balance in patients with fibromyalgia: a heart rate variability analysis. Arthritis Rheum 1998;41:1966-1971.

Moldofsky H. Sleep and pain. Sleep Med Rev 2001;5:385-396.

Moltner A, Holzl R, Strian F. Heart rate changes as an autonomic component of the pain response. Pain 1990;43:81-89.

Morgan BJ, Crabtree DC, Puleo DS, Badr MS, Toiber F, Skatrud JB. Neurocirculatory consequences of abrupt change in sleep state in humans. J Appl Physiol 1996;80:16271636.

Nuwer MR, Comi G, Emerson R, Fuglsang-Frederiksen A, Guerit JM, Hinrichs H, Ikeda A, Luccas FJ, Rappelsburger P. IFCN standards for digital recording of clinical EEG. International Federation of Clinical Neurophysiology. Electroencephalogr Clin Neurophysiol 1998;106:259-261.

Onen SH, Onen F, Courpron P, Dubray C. How pain and analgesics disturb sleep. Clin J Pain 2005;21:422-431.

Pagani M, Lombardi F, Guzzetti S, Sandrone G, Rimoldi O, Malfatto G, Cerutti S, Malliani A. Power spectral density of heart rate variability as an index of sympatho-vagal interaction in normal and hypertensive subjects. J Hypertens Suppl 1984;2:S383-385.

Pagani M, Rimoldi O, Malliani A. Low-frequency components of cardiovascular variabilities as markers of sympathetic modulation. Trends Pharmacol Sci 1992;13:50-54.

Paine P, Kishor J, Worthen SF, Gregory LJ, Aziz Q. Exploring relationships for visceral and somatic pain with autonomic control and personality. Pain 2009;144:236-244.

Perchet C, Godinho F, Mazza S, Frot M, Legrain V, Magnin M, Garcia-Larrea L. Evoked potentials to nociceptive stimuli delivered by $\mathrm{CO} 2$ or Nd:YAP lasers. Clin Neurophysiol 2008; 119(11):2615-22.

Pichot V, Buffiere S, Gaspoz JM, Costes F, Molliex S, Duverney D, Roche F, Barthelemy JC. Wavelet transform of heart rate variability to assess autonomic nervous system activity does not predict arousal from general anesthesia. Can J Anaesth 2001;48:859-863. 
Pichot V, Gaspoz JM, Molliex S, Antoniadis A, Busso T, Roche F, Costes F, Quintin L, Lacour JR, Barthelemy JC. Wavelet transform to quantify heart rate variability and to assess its instantaneous changes. J Appl Physiol 1999;86:1081-1091.

Rechtschaffen A, Kales A. Manual of standardarized terminology. Washington DC: US Government Printing Office, National Institute of health publications 1968.

Sarzi-Puttini P, Atzeni F, Diana A, Doria A, Furlan R. Increased neural sympathetic activation in fibromyalgia syndrome. Ann N Y Acad Sci 2006;1069:109-117.

Sforza E, Jouny C, Ibanez V. Cardiac activation during arousal in humans: further evidence for hierarchy in the arousal response. Clin Neurophysiol 2000;111:1611-1619.

Sforza E, Juony C, Ibanez V. Time-dependent variation in cerebral and autonomic activity during periodic leg movements in sleep: implications for arousal mechanisms. Clin Neurophysiol 2002;113:883-891.

Sforza E, Nicolas A, Lavigne G, Gosselin A, Petit D, Montplaisir J. EEG and cardiac activation during periodic leg movements in sleep: support for a hierarchy of arousal responses. Neurology 1999;52:786-791.

Sforza E, Pichot V, Barthelemy JC, Haba-Rubio J, Roche F. Cardiovascular variability during periodic leg movements: a spectral analysis approach. Clin Neurophysiol 2005;116:10961104.

Steriade M, Nunez A, Amzica F. Intracellular analysis of relations between the slow $(<1 \mathrm{~Hz})$ neocortical oscillation and other sleep rhythms of the electroencephalogram. J Neurosci 1993;13:3266-3283.

Task Force of the European Society of Cardiology and the North American Society of Pacing and Electrophysiology. Heart rate variability: standards of measurement, physiological interpretation and clinical use. Circulation 1996;93:1043-1065.

Thomas, RJ, Mietus, JE, Crofford, LJ. Impaired sleep quality in fibromyalgia: Detection and quantification with ECG-based cardiopulmonary coupling spectrograms. Sleep Medicine 2010; $11: 497-501$.

Trinder J, Kleiman J, Carrington M, Smith S, Breen S, Tan N, Kim Y. Autonomic activity during human sleep as a function of time and sleep stage. J Sleep Res 2001b;10:253-264.

Trinder J, Padula M, Berlowitz D, Kleiman J, Breen S, Rochford P, Worsnop C, Thompson B, Pierce R. Cardiac and respiratory activity at arousal from sleep under controlled ventilation conditions. J Appl Physiol 2001a;90:1455-1463. 
Truini A, Galeotti F, Cruccu G, Garcia-Larrea L. Inhibition of cortical responses to Adelta inputs by a preceding C-related response: testing the "first come, first served" hypothesis of cortical laser evoked potentials. Pain 2007;131:341-347.

Vanoli E, Adamson PB, Ba L, Pinna GD, Lazzara R, Orr WC. Heart rate variability during specific sleep stages. A comparison of healthy subjects with patients after myocardial infarction. Circulation 1995;91:1918-1922.

Vaughn BV, Quint SR, Messenheimer JA, Robertson KR. Heart period variability in sleep. Electroencephalogr Clin Neurophysiol 1995;94:155-162.

Versace F, Mozzato M, De Min Tona G, Cavallero C, Stegagno L. Heart rate variability during sleep as a function of the sleep cycle. Biol Psychol 2003;63:149-162.

Wiklund U, Akay M, Niklasson U. Short-term analysis of heart-rate variability by adapted wavelet transforms. IEEE Eng Med Biol Mag 1997;16:113-118, 138. 


\section{Table 1}

Characteristic and sleep parameters of 11 remaining healthy volunteers (mean \pm standard deviation (SD)).

\begin{tabular}{llll}
\hline & Mean & SD & Range \\
\hline Age & 32.8 & 7.3 & {$[18-47]$} \\
Total sleep time (min) & 397.9 & 60.3 & {$[272-507]$} \\
GHQ-28 Score & 2.8 & 0.5 & {$[2.3-3.5]$} \\
& & & \\
Number of analysed stimulations during per subject: & & & \\
Wakefulness & 20.1 & 20.2 & {$[0-66]$} \\
Stage 2 & 29.5 & 9.3 & {$[5-60]$} \\
Paradoxical sleep & 21.3 & 14.3 & {$[4-40]$} \\
Slow wave sleep & 9.3 & 10.3 & {$[0-33]$} \\
Total number & 80.1 & 30.6 & {$[44-143]$} \\
& & & \\
Percentage of arousal after stimulation per subject in: & & & \\
Stage 2 & 28.8 & 17.1 & {$[2.4-61.1]$} \\
Paradoxical sleep & 21.3 & 27.0 & {$[0-100]$} \\
Slow wave sleep & 14.2 & 19.1 & {$[0-50]$} \\
\hline
\end{tabular}

GHQ-28, general health Golberg and Hillier questionnaire. 


\section{Figure}

Figure 1. Examples of behavioural reactions to laser stimuli. The upper traces correspond to EEG, and the three bottom traces to EOG, chin EMG and EKG. The arrow and dotted line indicate the onset of the stimulus (5 ms duration). (A) slow wave sleep, no cortical reaction to the stimulus and (B) stage 2, cortical arousal.

Figure 2. A representative example of (A) RR intervals (RR), (B) low $\left(\mathrm{LF}^{\mathrm{WV}}\right)$ and $(\mathrm{C})$ high frequency $\left(\mathrm{HF}^{\mathrm{WV}}\right.$ ) wavelet power and $(\mathrm{D}) \mathrm{LF}^{\mathrm{WV}} / \mathrm{HF}^{\mathrm{WV}}$ ratio before and after an isolated nociceptive stimulation in one subject during sleep stage 2 . Time (s) in abscissa refer to the time of one analysed period during polysomnographic recording. Dotted line represents nociceptive stimulation.

Figure 3. Comparisons between states of vigilance: (A) RR intervals (RR), (B) low ( $\mathrm{LF}^{\mathrm{WV}}$ ) and $(\mathrm{C})$ high frequency $\left(\mathrm{HF}^{\mathrm{WV}}\right)$ wavelet power and $(\mathrm{D}) \mathrm{LF}^{\mathrm{WV}} / \mathrm{HF}^{\mathrm{WV}}$ ratio before and after nociceptive stimulations (mean $\pm \mathrm{SEM}$ ). ${ }^{*} p<0.05$ mean $\mathrm{RR}$ after the stimulation in comparison to pre stimulation value. An overall effect appeared in $\mathrm{LF}^{\mathrm{WV}}$ and in $\mathrm{LF}^{\mathrm{WV}} / \mathrm{HF}^{\mathrm{WV}}$ ratio between before and after stimulation. Nociceptive-induced RR decrease was preserved in all sleep stages, and this cardiac activation was related to a sympathetic reactivity.

Figure 4. Comparisons according to cortical arousals: (A) RR intervals (RR), (B) low (LF ${ }^{\mathrm{WV}}$ ) and $(\mathrm{C})$ high frequency $\left(\mathrm{HF}^{\mathrm{WV}}\right)$ wavelet power and $(\mathrm{D}) \mathrm{LF}^{\mathrm{WV}} / \mathrm{HF}^{\mathrm{WV}}$ ratio before and after nociceptive stimulation during no cortical and cortical arousals (mean $\pm \mathrm{SEM}$ ). ${ }^{*} p<0.05$ mean RR during post stimulation in comparison to pre stimulations. An overall effect appeared in $\mathrm{LF}^{\mathrm{WV}}$ and in $\mathrm{LF}^{\mathrm{WV}} / \mathrm{HF}^{\mathrm{WV}}$ ratio between before and after stimulation. Nociceptive stimulation induced a sympathetic-dependent RR decrease which was higher when nociceptive stimuli produced cortical arousals. 


\section{A}

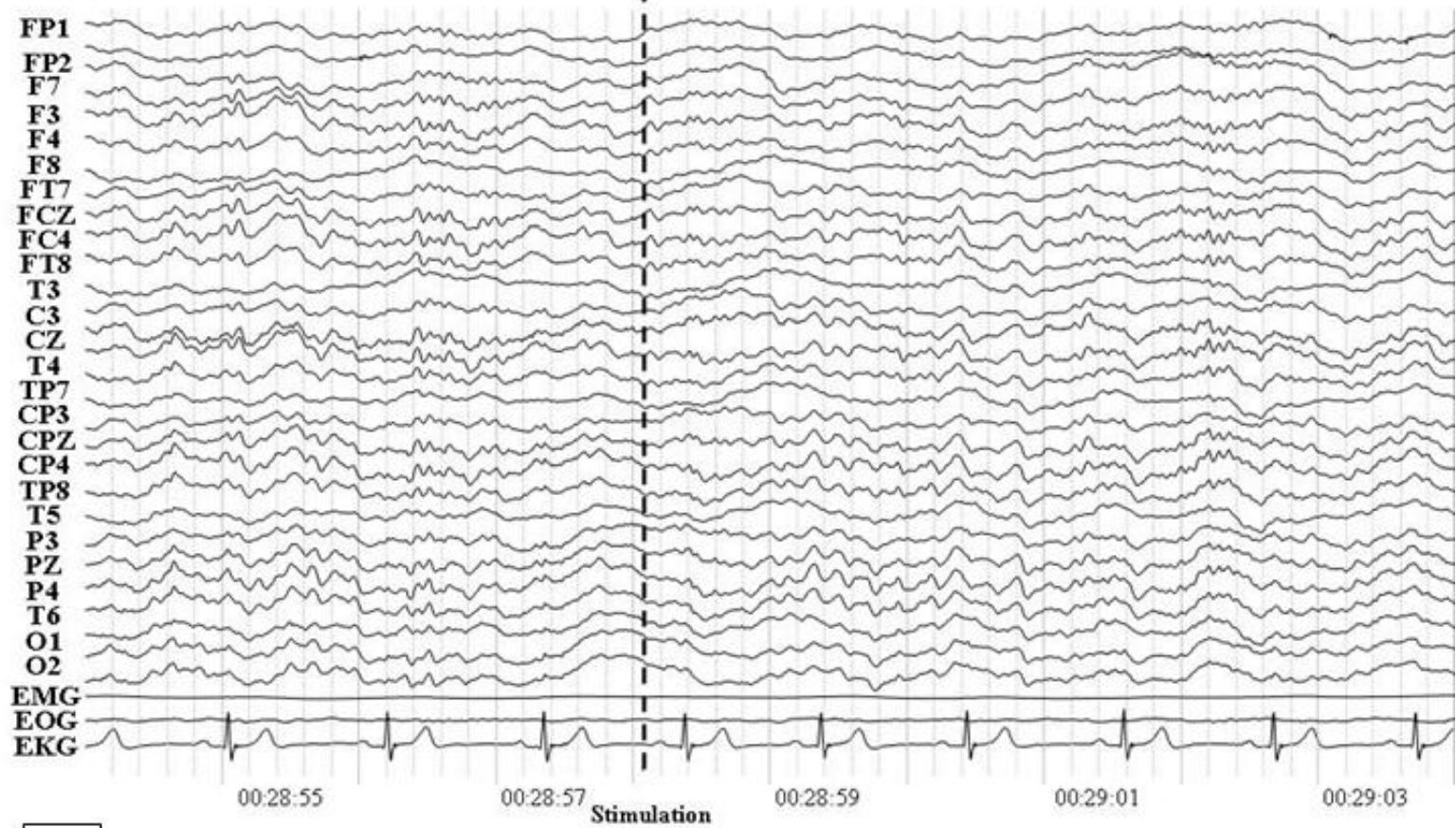

B

$128 \mu \mathrm{V}$

10 s

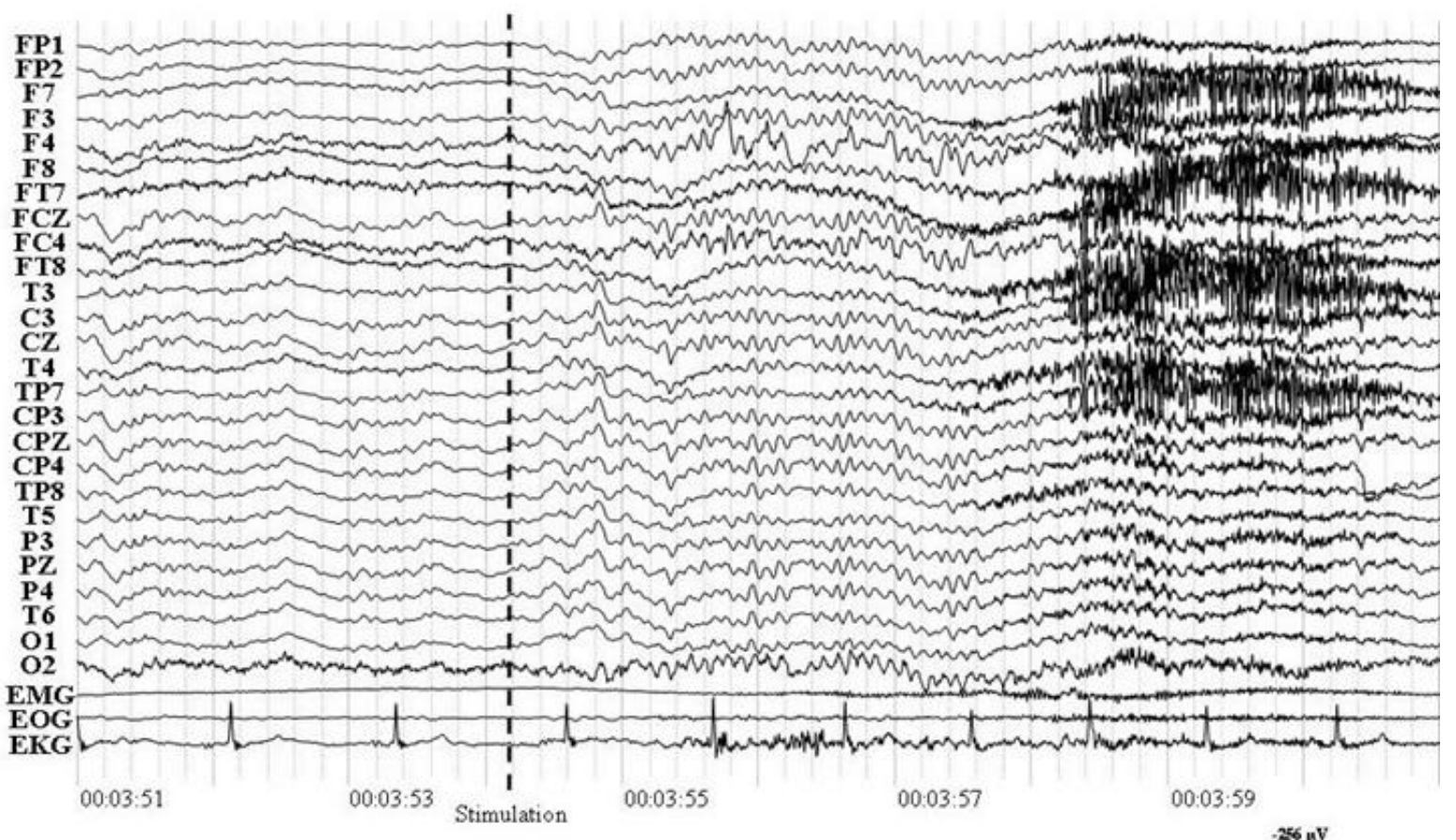



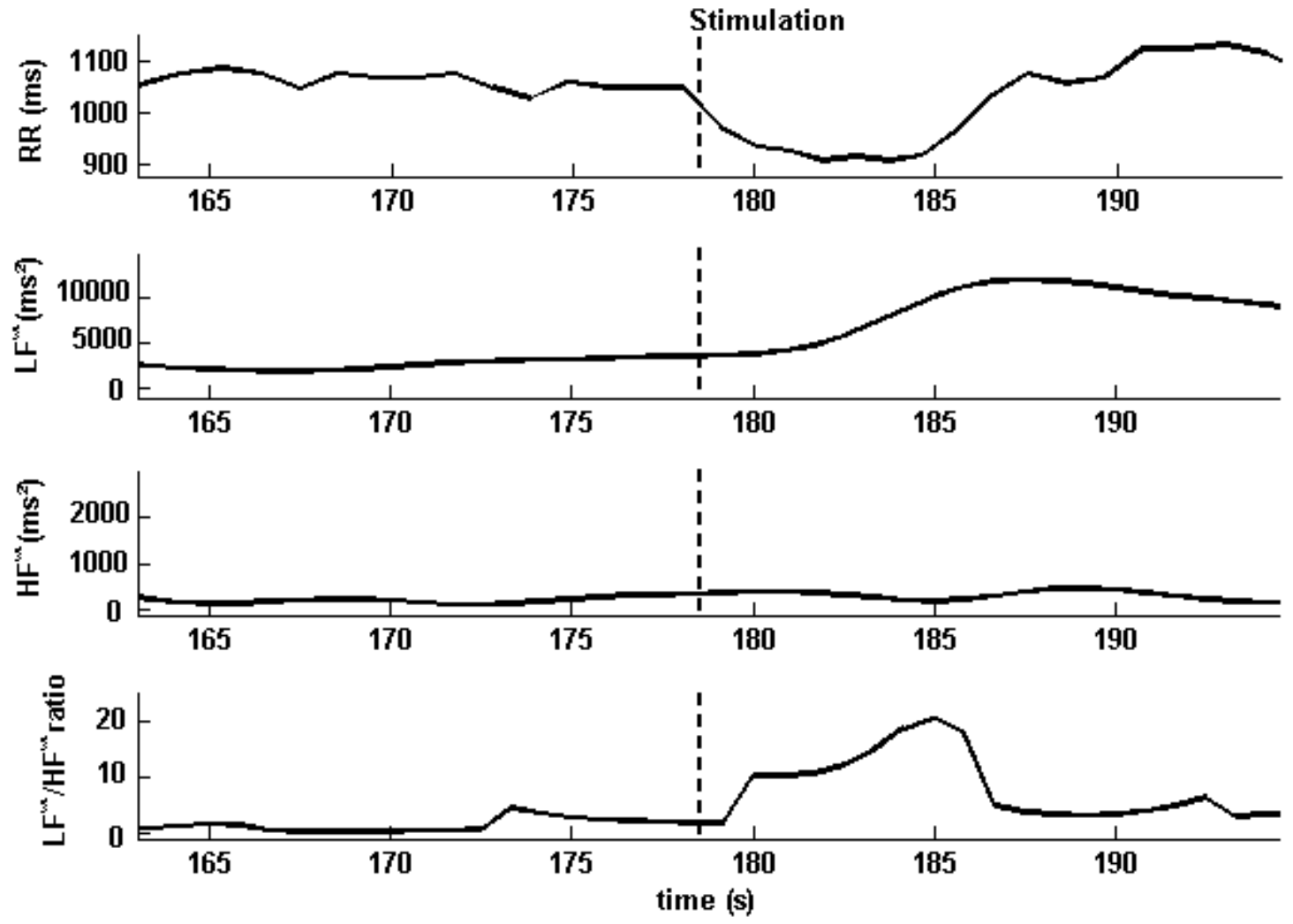

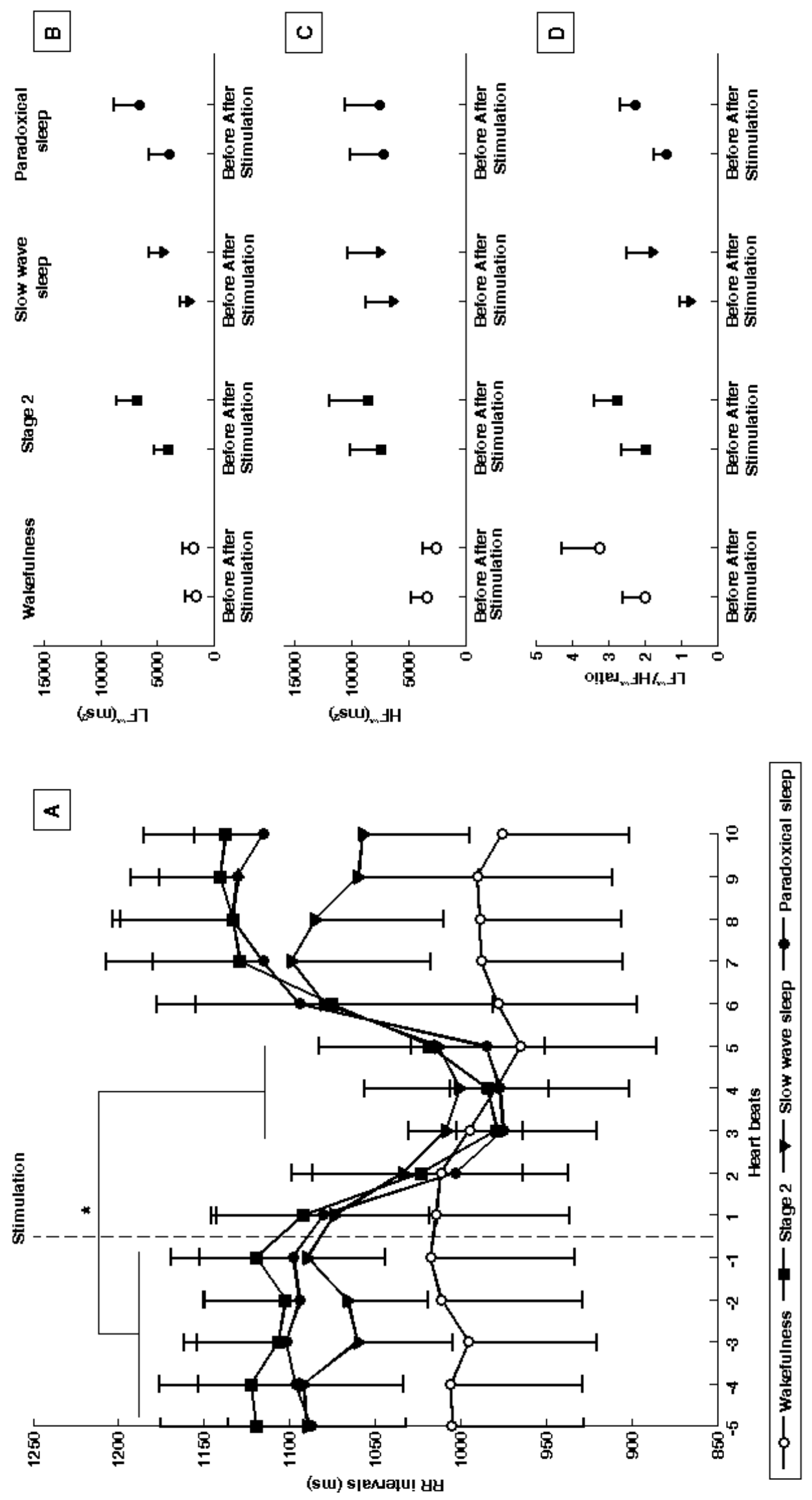

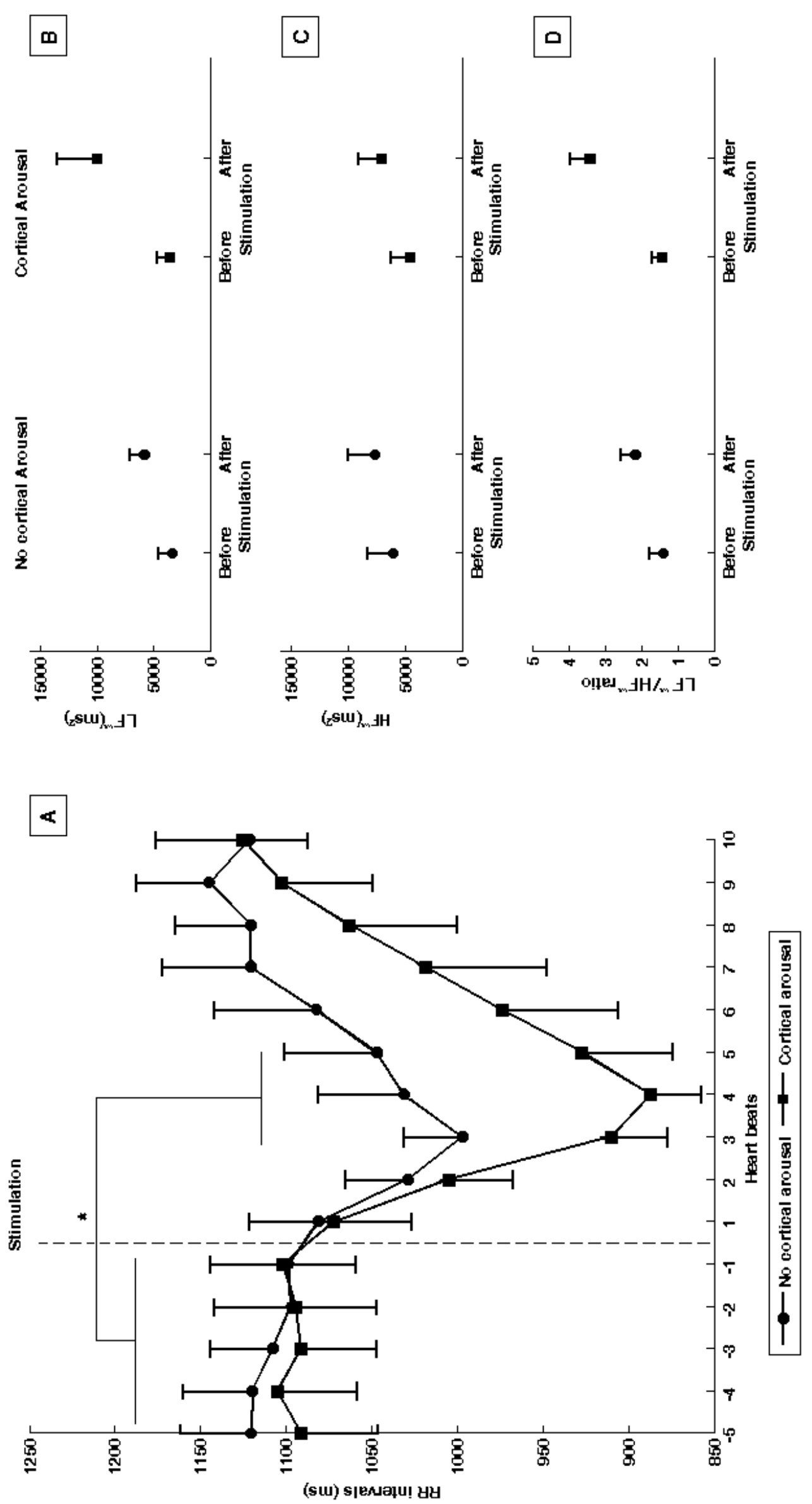